\title{
Different Roles of the CD2 and LFA-1 T-Cell Co-receptors for Regulating Cytotoxic, Proliferative, and Cytokine Responses of Human $\mathrm{V} \gamma \mathbf{9} / \mathrm{V} \delta 2 \mathrm{~T}$ Cells
}

\author{
Peng Wang ${ }^{1}$ and Miroslav Malkovsky ${ }^{1,2,3}$ \\ ${ }^{1}$ Department of Medical Microbiology and Immunology, University of Wisconsin \\ Medical School, Madison, Wisconsin, U.S.A. \\ ${ }^{2}$ University of Wisconsin Comprehensive Cancer Center and ${ }^{3}$ Wisconsin Regional \\ Primate Research Center, Madison, Wisconsin, U.S.A.
}

Accepted December 27, 1999.

\begin{abstract}
Background: Human V $\gamma 9 / \mathrm{V} \delta 2 \mathrm{~T}$ lymphocytes recognize nonpeptidic antigens in a manner distinct from the classical antigen recognition by $\alpha \beta$ T cells. The apparent lack of major histocompatibility (MHC) restriction and antigen processing allows very fast responses against pathogenic insults. To address the potential functional requirement for accessory molecules, we investigated the roles of the CD2 and lymphocyte functionassociated antigen (LFA)-1 T-cell co-receptors in antigen-induced activities of human $\mathrm{V} \gamma 9 / \mathrm{V} \delta 2 \mathrm{~T}$-cell clones. Materials and Methods: Human peripheral blood V $\gamma 9 / \mathrm{V} \delta 2 \mathrm{~T}$ lymphocytes were cloned and their cytotoxicity against Daudi lymphoma was measured by a standard ${ }^{51} \mathrm{Cr}$-release assay. The responses of $\mathrm{V} \gamma 9 / \mathrm{V} \delta 2 \mathrm{~T}$ lymphocytes to nonpeptidic antigens were assessed using DNA synthesis and cytokine ELISA assays. Monoclonal antibodies specific for various molecules with potential T-cell accessory functions were utilized in blocking assays.
\end{abstract}

Results: All of our $\mathrm{V} \gamma 9 / \mathrm{V} \delta 2 \mathrm{~T}$-cell clones displayed the Thl phenotype. The anti-LFA-1 antibody strongly inhibited the cytotoxicity of $\mathrm{V} \gamma 9 / \mathrm{V} \delta 2 \mathrm{~T}$ cells against Daudi B-cell lymphoma; whereas, it had no influence on the antigen-induced cytokine release or proliferation. In contrast, antibodies against CD2 and LFA-3 had no effect on the lytic activity of $\mathrm{V} \gamma 9 / \mathrm{V} \delta 2 \mathrm{~T}$ cells, but strongly inhibited the cytokine release and proliferation. However, the CD2-LFA-3 interaction was not an absolute requirement for the cytokine release and the DNA synthetic activity of antigen-stimulated $\mathrm{V} \gamma 9 / \mathrm{V} \delta 2 \mathrm{~T}$ cells, since the inhibitory effect could be reversed by addition of exogenous interleukin 2 (IL-2). Conclusions: These novel observations indicate that the signals generated by different accessory molecules and IL-2 can contribute in an integrated fashion to the regulation of $\mathrm{V} \gamma 9 / \mathrm{V} \delta 2 \mathrm{~T}$ cells. These interactions may be important for the effectiveness of $\mathrm{V} \gamma 9 / \mathrm{V} \delta 2 \mathrm{~T}$-cell responses.

\section{Introduction}

Human $\mathrm{T}$ cells expressing the $\mathrm{V} \gamma 9$ and $\mathrm{V} \delta 2$ chains of the T-cell receptor (TCR) form a small subset of circulating $\mathrm{T}$ cells (1). The identified antigens for these cells belong to the group of nonpeptidic phosphoantigens

Address correspondence and reprint requests to: Miroslav Malkovsky, Department of Medical Microbiology and Immunology, University of Wisconsin Medical School, 1300 University Avenue, Madison, WI 53706, U.S.A. Phone and fax: 608-263-6316; E-mail:

mmalkovs@facstaff.wisc.edu
(2) and alkylamines (3). The recognition of nonpeptidic antigens is mediated through the $\mathrm{V} \gamma 9 / \mathrm{V} \delta 2$ TCR (4). The structure of these antigens is very different from that of the major histocompatibility (MHC)-peptide complex (5) and, consequently, the serial trigger mode of activation of $\mathrm{T}$ cells may not be applicable to the $\mathrm{V} \gamma 9 / \mathrm{V} \delta 2$ subset (6). The recognition of peptide/MHC complex by the TCR is a key element in the activation of $\alpha \beta \mathrm{T}$ cells (7). However, the crosslinking of the $\alpha \beta$ TCRs alone appears to be insufficient for the full development of T-cell response (8) and many accessory 
molecules that contribute to the T-cell activation process have been identified (9).

Lymphocyte function-associated antigen (LFA)-1, a member of the integrin family, is expressed on T cells, B cells, granulocytes, and macrophages (10). Studies with $\alpha \beta$ T cells show that LFA-1 can mediate cell-to-cell adhesion and stimulate various intracellular processes (10). LFA-1 is important for target-cytotoxic $\alpha \beta$ T-cell interactions (11). LFA- 1 can also affect other cellular functions of $\alpha \beta$ T-cells, such as apoptosis, proliferation, cytokine production and antigen presentation (10). CD2 belongs to the immunoglobulin superfamily and is expressed on all subsets of $\mathrm{T}$ lymphocytes, natural killer (NK) and lymphokine-activated killer (LAK) cells (12). The CD2 ligand, LFA-3, is expressed on human lymphoid cells as a transmembrane-integrated form or phosphoinositol-linked form $(13,14)$. The CD2-LFA-3 interaction delivers an important costimulatory signal and strengthens the adhesion between interacting cells $(10,15)$. It has been demonstrated that antibodies against CD2 can inhibit the antigen-induced proliferation of $\alpha \beta$ T cells (10) and the cytotoxicity of CD8 $\alpha \beta$ T cells (15).

The signaling through the CD2 molecule is dependent on the TCR-associated $\zeta$ chain (16). However, there are interesting differences between $\alpha \beta \mathrm{T}$ cells and $\gamma \delta \mathrm{T}$ cells in this regard. For example, at least two monoclonal antibodies specific for different epitopes of CD2 are necessary to induce the activation of $\alpha \beta$ T cells (16); whereas, a single CD2 antibody is enough to activate $\gamma \delta \mathrm{T}$ cells (17). Moreover, the murine $\gamma \delta$ TCR associates with a distinct member of the $\zeta$ family, the $\gamma$ chain of the Fc $\varepsilon$ RI (reviewed in ref. 18) and, therefore, signaling through CD2 may operate differently in $\gamma \delta$ and $\alpha \beta \mathrm{T}$ cells. However, the situation in primates and other species is unclear.

Human $\mathrm{V} \gamma 9 / \mathrm{V} \delta 2 \mathrm{~T}$ cells recognize a broad spectrum of nonpeptidic antigens $(5,19)$. This recognition requires neither antigen processing nor the expression of MHC or MHCrelated molecules (20). Most $\mathrm{V} \gamma 9 / \mathrm{V} \delta 2 \mathrm{~T}$ cells can respond to nonpeptidic antigens in the absence of antigen-presenting cells (APCs). However, the presence of APCs can greatly enhance the $\mathrm{V} \gamma 9 / \mathrm{V} \delta 2 \mathrm{~T}$-cell response (20). This suggests that accessory molecules may be involved in these responses. Here we show for the first time that LFA-1 and CD2 have different roles in regulating the $\mathrm{V} \gamma 9 / \mathrm{V} \delta 2 \mathrm{~T}$-cell activities.

\section{Materials and Methods}

Cells and Cell Cultures

Cells were cultured in RPMI 1640 medium supplemented with $2 \mathrm{mM}$ L-glutamine, $100 \mathrm{IU} / \mathrm{ml}$ penicillin, $100 \mu \mathrm{g} / \mathrm{ml}$ streptomycin, and $10 \% \mathrm{fe}-$ tal bovine serum. The T-cell clones were generated using the method described elsewhere (21). The clonality was confirmed by gene scan analysis of CDR3 polymorphism (data not shown).

\section{Antibodies, IL-2, and FACS Analysis}

The V $\delta 2$-phycoerythrin (PE) antibody (clone B6.1), anti-CD28-PE antibody (clone CD28.2) and their isotype (immunoglobulin Gl (IgGl)PE, clone MOPC-21) control antibody were purchased from Pharmingen (San Diego, CA). The anti-CD2 (clone TS/18), anti-LFA-3 (clone TS2/9), anti-LFA-1 (clone TS1/22) and anti-intercellular adhesion molecule (ICAM)-1 (clone P2A4) monoclonal antibodies were purchased from Endogen (Woburn, MA). The unconjugated IgGl (clone MOPC-21) antibody was also purchased from Pharmingen. All the antibodies used in the blocking study were carrier and preservative-free. In the blocking studies, anti-CD2 antibody and anti-LFA-3 antibody were used at a concentration of $5 \mu \mathrm{g} / \mathrm{ml}$. The anti-LFA- 1 antibody and IgGl antibody were used at a concentration of $10 \mu \mathrm{g} / \mathrm{ml}$. In some experiments, recombinant interleukin 2 (IL-2) was used to reverse the inhibitory effects. One hundred units (defined as described; 22) per one $\mathrm{ml}$ of culture were used. Analysis of surface antigen expression was performed by flow cytometry (21).

TNF- $\alpha$ Assay

$10^{4}$ responder cells were stimulated with the indicated concentrations of isopentenyl pyrophosphate (IPP) purchased from Sigma (Harz, Germany). The supernatants were collected $6 \mathrm{hr}$ later. The concentration of tumor necrosis factor (TNF)- $\alpha$ was determined using the ELISA assay kit from R\&D Systems (Minneapolis, MN) following the manufacturer's instructions. The blocking or control antibodies were added to the culture at the initiation of antigen exposure.

\section{Proliferation Assay}

Proliferation assay was performed in 96-well round bottom plates using $10^{5} /$ well responder 
cells and $10^{5} /$ well irradiated LCL721 cells (11,000 rads, ${ }^{137} \mathrm{Cs}$ source) as feeders. $48 \mathrm{hr}$ after IPP stimulation, $1 \mu \mathrm{Ci} /$ well of $\left[\right.$ methyl $\left.{ }^{3} \mathrm{H}\right]$ thymidine (2.6-3.2 $\mathrm{TBq} / \mathrm{mM}$, Amersham Pharmacia Biotech, Piscataway, NJ) was added, the cells were harvested after additional $18 \mathrm{hr}$ and DNA synthesis was measured as described (23). The blocking or control antibodies were added to the culture at the initiation of antigen exposure. To assess the produced IL-2 levels, the supernatants were diluted $1: 4$ with medium, cultured with CTLL-2 cells and their DNA synthetic response was measured as described (23).

\section{Cytotoxicity Assay}

Daudi cells were labeled with $100 \mu \mathrm{Ci}$ $\mathrm{Na}_{2}\left[{ }^{51} \mathrm{Cr}\right] \mathrm{O}_{4}(7.4-18.5 \mathrm{GBq} / \mathrm{mg} \mathrm{Cr}$, Amersham Pharmacia Biotech.) for $1 \mathrm{hr}$ at $37^{\circ} \mathrm{C}$. After three washes with phosphate-buffered saline (PBS) Daudi cells $\left(10^{4} /\right.$ well $)$ were incubated in 96well round bottom plates with $\mathrm{V} \gamma 9 / \mathrm{V} \delta 2 \mathrm{~T}$ cells at the indicated effector:target $(\mathrm{E}: \mathrm{T})$ cell ratios. The cells were incubated for $6 \mathrm{hr}$ at $37^{\circ} \mathrm{C}$, and the specific lysis was determined as described (24). The blocking or control antibodies were added to the Daudi cells just before mixing with the effector $\mathrm{V} \gamma 9 / \mathrm{V} \delta 2 \mathrm{~T}$ cells.

\section{Analysis of TCR Downregulation}

The $\mathrm{V} \gamma 9 / \mathrm{V} \delta 2$ T-cell clones were stimulated with the indicated concentrations of IPP. Twenty-four hours later, cells were harvested and washed three times with ice-cold PBS before staining. Cells were stained with V $\delta 2-\mathrm{PE}$ on ice for $30 \mathrm{~min}$, washed three times with ice-cold PBS and analyzed by flow cytometry (FASCan ${ }^{\circledR}$ Flow Cytometer, Becton Dickinson, San Jose, CA) using the Quantum Simple Cellular kit following the instructions of the manufacturer (Flow Cytometry Standards Corp., San Juan, Puerto Rico). Dead cells were excluded by propidium iodide (PI) staining. Data analysis was performed using CELLQuest (Becton Dickinson).

\section{Evaluation of Results}

The error bars in the figures indicate calculated standard errors (SE) of the measurement. The statistical significance of differences was calculated by Student's t-test. A $p$ value of less than 0.05 was considered significant.

\section{Results}

Antigen Presenting Cells Are Required for Optimal

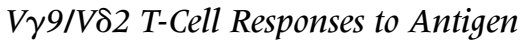

Human $\mathrm{V} \gamma 9 / \mathrm{V} \delta 2 \mathrm{~T}$ cells recognize nonpeptidic antigens in a MHC-independent manner. Previous studies showed that some $\mathrm{V} \gamma 9 / \mathrm{V} \delta 2 \mathrm{~T}$ cells can respond to IPP in the absence of APCs (20). To examine the APC requirements in our $\mathrm{V} \gamma 9 / \mathrm{V} \delta 2 \mathrm{~T}$-cell clones, six clones were stimulated with IPP in the presence or absence of APCs (irradiated LCL721 cells). Four out of six clones responded to IPP in the absence of APCs (Fig. 1A). Nevertheless, the presence of APCs

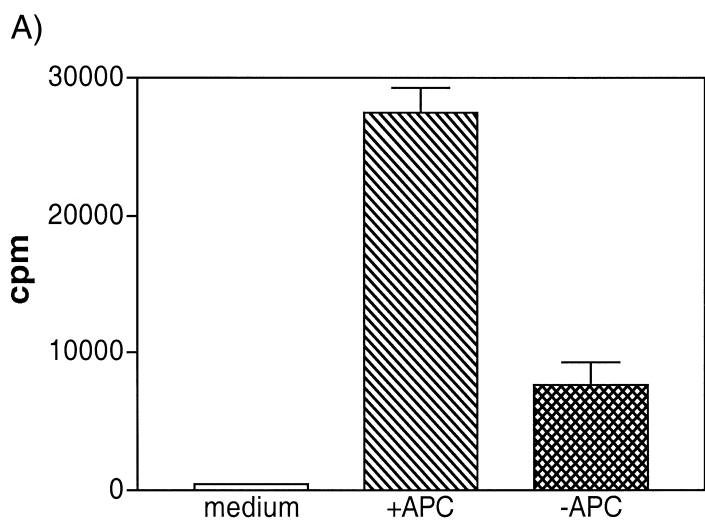

B)

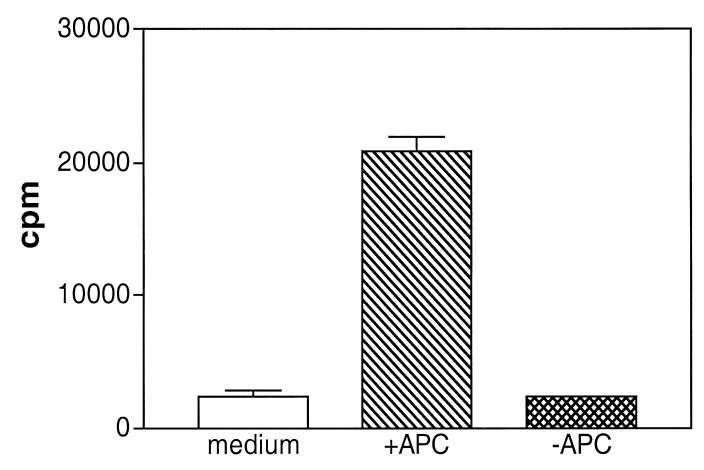

Fig. 1. Optimal $\mathrm{V} \gamma \mathbf{\gamma} / \mathrm{V} \delta 2 \mathrm{~T}$-cell responses to IPP require the presence of APC. $\mathrm{V} \gamma 9 / \mathrm{V} \delta 2 \mathrm{~T}$-cell clones were stimulated with $20 \mu \mathrm{M}$ IPP either with or without irradiated LCL72 1 cells as APCs. Results of two representative clones are shown here. (A) Clone ROI responded to isopenteryl pyrophosphate (IPP) in the absence of antigen-presenting cells (APCs) $(p<0.0001$ compared with medium control), but APCs strongly enhanced their response $(p<0.004$ when comparing cultures with or without APCs). (B) Clone RO26 required the presence of APCs to mount the DNA synthetic response to IPP. No significant DNA synthesis $(p>0.05)$ was measured in the absence of APCs. However, DNA synthesis was clearly detectable $(p<0.003)$ in the presence of APCs. Medium control: $\mathrm{V} \gamma 9 / \mathrm{V} \delta 2 \mathrm{~T}$ cells cultured with APCs in the absence of the antigen. cpm, counts per minute. 
greatly enhanced their responses. However, two out of six clones absolutely required the presence of APCs for the antigen-induced DNA synthetic response to occur (Fig. 1B). This observation indicates that, at least in some $\mathrm{V} \gamma 9 / \mathrm{V} \delta 2 \mathrm{~T}$ cells, surface molecules other than the TCR may be involved in the activation process.

Subsequently, we examined the expression of several of costimulatory molecules, namely CD28, CD2, LFA-1 and LFA-3, by flow cytometry. None of the tested clones express CD28 (Fig. 2 ), an observation compatible with the results of Gramzinski et al. (25), suggesting that CD28 may not be involved in $\mathrm{V} \gamma 9 / \mathrm{V} \delta 2$ T-cell responses. All tested clones expressed CD2, LFA-1 and LFA-3 (Fig. 2). Since CD2 and LFA-1 were expressed on all these clones, we investigated their potential roles in $\mathrm{V} \gamma 9 / \mathrm{V} \delta 2 \mathrm{~T}$-cell responses.

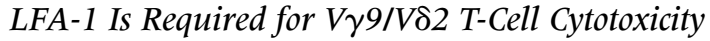 Against Daudi B-Cell Lymphoma}

$\mathrm{V} \gamma 9 / \mathrm{V} \delta 2 \mathrm{~T}$ cells are able to kill lymphoma targets such as Daudi cells (21). It has been shown
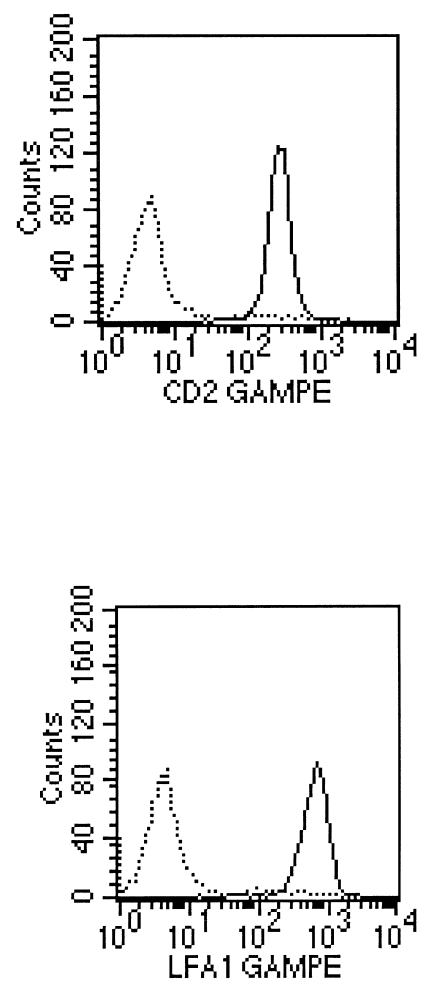

Fig. 2. $\quad \mathrm{V} \gamma 9 / \mathrm{V} \delta 2 \mathrm{~T}$-cell clones express CD2, LFA1 and LFA-3, but not CD28. $\mathrm{V} \gamma 9 / \mathrm{V} \delta 2 \mathrm{~T}$ cells were first stained with anti-CD2, anti-LFA-1 and antiLFA-3 (solid line) or the nonspecific isotype control (dotted line) followed by staining with the goatanti-mouse phycoerythrin (GAM-PE) antibody. The that both LFA-1 and CD2 are involved in the cytotoxic activity of CD8 positive $\mathrm{T}$ cells and NK cells (10). To determine the role of LFA-1 and CD2 in the lysis of target cells by $\mathrm{V} \gamma 9 / \mathrm{V} \delta 2$ $\mathrm{T}$ cells, we performed standard cytotoxicity assays in the presence of specific antibodies. The anti-LFA-1 antibody effectively inhibited the lysis of Daudi lymphoma targets by $\mathrm{V} \gamma 9 / \mathrm{V} \delta 2 \mathrm{~T}$ cells (Fig. 3A). However, neither anti-LFA-3 (Fig. 3B) nor anti-CD2 (not shown) had any significant influence on the target lysis.

\section{The CD2-LFA-3 Interaction Is Required for the} Vy9/V82 T-Cell Response to IPP

Some CD2 antibodies can strongly inhibit the $\alpha \beta$ T-cell antigenic response (10). We examined whether the relevant antibodies can block the response of $\mathrm{V} \gamma 9 / \mathrm{V} \delta 2 \mathrm{~T}$ cells to IPP. First, we determined optimal concentrations of anti-CD2 and anti-LFA-3 for blocking (Fig. 4). V $\gamma 9 / \mathrm{V} \delta 2$ $\mathrm{T}$ cells were stimulated with IPP in the presence of anti-CD2 or anti-LFA-3. Both antibodies strongly inhibited the antigen-induced
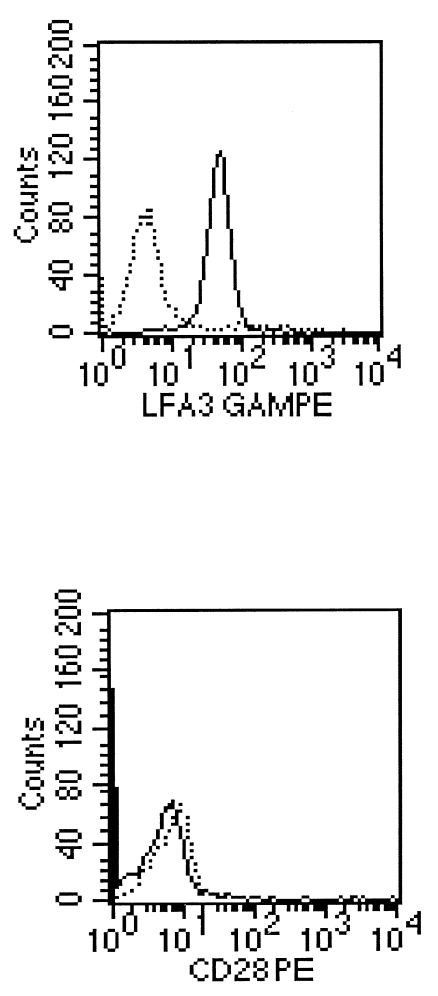

clones were also stained directly with anti-CD28$\mathrm{PE}$ (solid line) and the corresponding isotype-PE control (dotted line). Very similar results were obtained with all tested clones. The given data illustrate the staining of clone ROI. 
A)

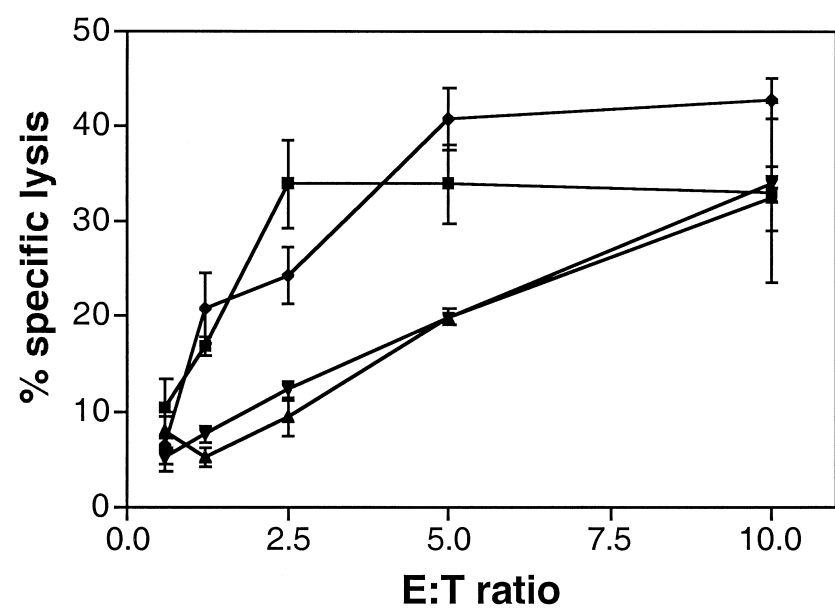

$\longrightarrow$ No $A b$

$\multimap \lg G 1$

$\longrightarrow$ LFA-1

$\rightarrow$ LFA-1+ICAM-1

B)

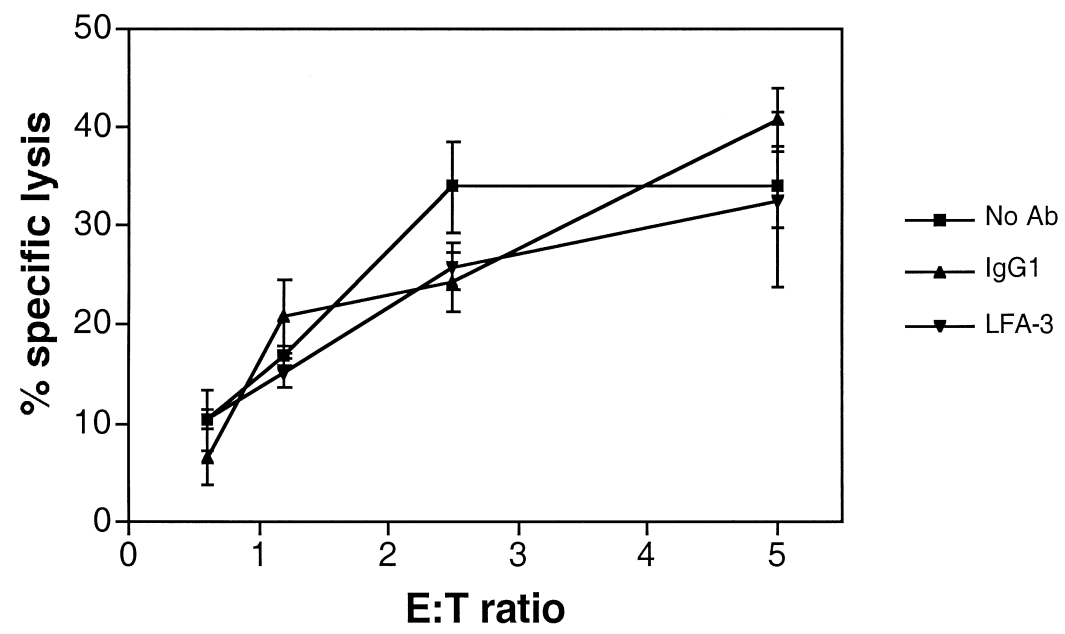

Fig. 3. LFA-1 is required for $\mathrm{V} \gamma \mathbf{9} / \mathrm{V} \delta 2 \mathrm{~T}$ cell $\mathrm{cy}-$ totoxicity. The results represent the lysis of Daudi cells by clone RO5. The assays were performed at the described E:T (effector to target cell) ratios in the presence of indicated antibody. (A) Anti-lymphocyte function-associated antigen 1 (LFA-1) inhibited the killing of target cells; whereas, antiLFA-3 (B) had no influence $(p>0.05)$. For example, at the E:T ratio of 5 , the statistical significance of the inhibition by anti-LFA-1 was at the level of $p<0.03$, when compared with "no antibody present (No $\mathrm{AB}$ )" and $p<0.004$ in comparison with nonspecific control immunoglobulin Gl (IgG1). Very similar results were obtained in repeated experiments with three different clones (RO5, 12.3.4 and 12.3.7). Similar to anti-LFA-3, the presence of anti-CD2 also did not influence the target lysis (not shown). ICAM-1, intercellular adhesion molecule 1 . 


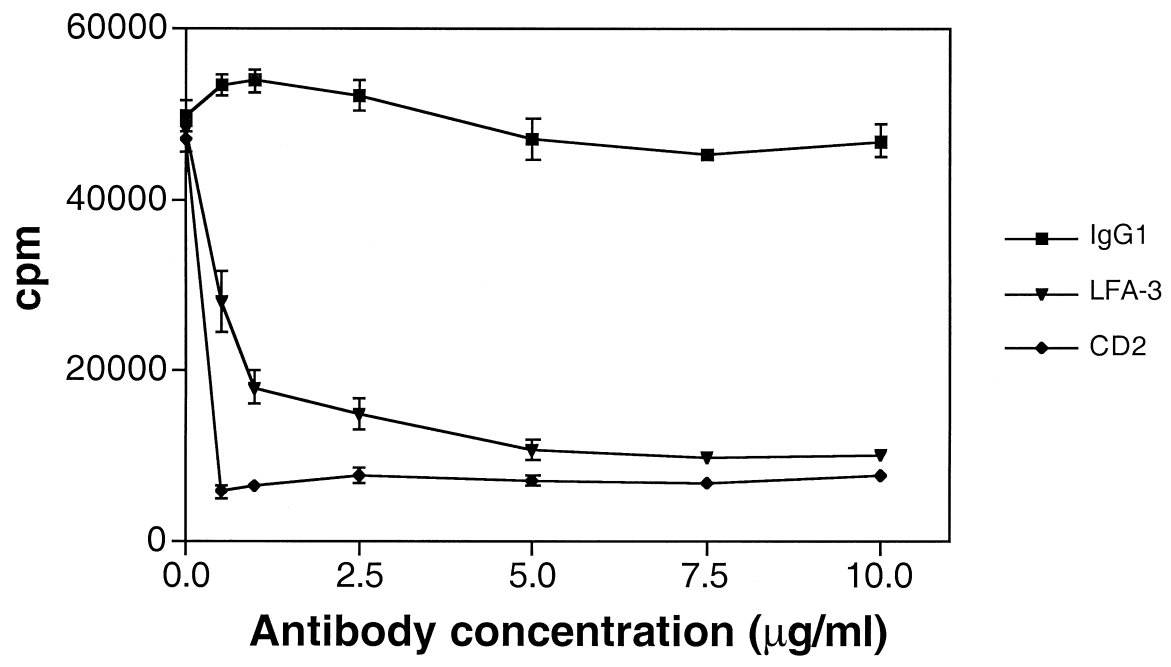

Fig. 4. The assessment of optimal blocking concentration of anti-CD2 and anti-LFA-3. $\mathrm{V} \gamma 9 / \mathrm{V} \delta 2 \mathrm{~T}$ cells were stimulated with $10 \mu \mathrm{M}$ of isopentenyl pyrophosphate (IPP) using irradiated LCL72 1 cells as antigen-presenting cells. Anti-CD2, anti-LFA-3, or the isotype control antibody was

DNA synthetic response (Fig. 5A). Since TNF- $\alpha$ is a predominant cytokine produced by antigen-stimulated $\mathrm{V} \gamma 9 / \mathrm{V} \delta 2 \mathrm{~T}$ cells (19), in parallel experiments, we investigated the influence of anti-CD2, anti-LFA-3 and anti-LFA-1 on the production of TNF- $\alpha$. The TNF $\alpha$ production was strongly inhibited by anti-CD2 and antiLFA-3 (Fig. 5C). In contrast, anti-LFA-1 had negligible influence on both the proliferative response of $\mathrm{V} \gamma 9 / \mathrm{V} \delta 2 \mathrm{~T}$ cells (Fig. $5 \mathrm{~B}$ ) and the TNF- $\alpha$ production (Fig. 5D).

Similar to $\alpha \beta$ T cells, $\gamma \delta$ T cells have been categorized as Th1 or Th2 cells according to their cytokine profile (26). We analyzed the secretion of interferon (IFN) $-\gamma$ by $\mathrm{V} \gamma 9 / \mathrm{V} \delta 2 \mathrm{~T}$-cell clones. All tested $\mathrm{V} \gamma 9 / \mathrm{V} \delta 2$ T-cell clones released high levels of IFN- $\gamma$ upon stimulation with IPP (data not shown), which is consistent with the Thl phenotype (26).

\section{IL-2 Can Restore the Vy9/V82 T-Cell Response to IPP}

There was a possibility that the CD2/LFA-3 inhibitory effect was due to a decreased production of proliferative cytokines, in particular of IL-2. V $\gamma 9 / \mathrm{V} \delta 2 \mathrm{~T}$ cells were stimulated with IPP in the presence of the anti-CD2 or control antibody. Twenty-four hours later, the supernatants from the cultures were removed and used to culture IL-2-dependent CTLL-2 cells. The supernatants from anti-CD2-treated cells added to the culture at the indicated concentration. The V $\gamma 9 / \mathrm{V} \delta 2 \mathrm{~T}$-cell antigenic response was assessed by measuring DNA synthesis. For example, anti-CD2 effectively inhibited the V $\gamma 9 / \mathrm{V} \delta 2 \mathrm{~T}$-cell response ( $>90 \%$ inhibition) at a concentration as low as $0.5 \mu \mathrm{g} / \mathrm{ml}(p<0.0001)$.

had substantially lower capacity to support the growth of CTLL-2 cells (Fig. 6), suggesting a potential deficit of IL-2. Since it was not easy in this system to exclude the involvement of other cytokines or other mechanisms, we examined whether the addition of exogenous IL-2 could restore the $\mathrm{V} \gamma 9 / \mathrm{V} \delta 2$ T-cells response to IPP. Both anti-CD2 (Fig. 7A) and anti-LFA-3treated, IPP-stimulated $\mathrm{V} \gamma 9 / \mathrm{V} \delta 2 \mathrm{~T}$ cells (Fig. 7B) released substantial amount of TNF- $\alpha$ in the presence of exogenous IL-2. The restoration of the TNF- $\alpha$ release was between approximately $50 \%$ (Fig. 7A) and $100 \%$ (Fig. 7B) in different experiments. It is noteworthy that the $\mathrm{V} \gamma \mathrm{9} / \mathrm{V} \delta 2$ T-cell clones did not secrete measurable levels of TNF- $\alpha$ when exposed to IL-2 in the absence of IPP stimulation.

\section{Anti-CD2 and anti-LFA-3 Antibodies Do Not Influence the Antigen-induced TCR Downregulation}

The antigenic activation of $\mathrm{T}$ cells is accompanied by a significant downregulation of the cell surface TCRs (27). This TCR downregulation process can be modulated by the signal delivered through costimulatory molecules (28). Since anti-CD2 or anti-LFA-3 inhibited the response of $\mathrm{V} \gamma 9 / \mathrm{V} \delta 2 \mathrm{~T}$ cells to IPP, we investigated whether or not the antibodies also influenced the IPP-induced downregulation of TCRs. The level of TCR downregulation in the 


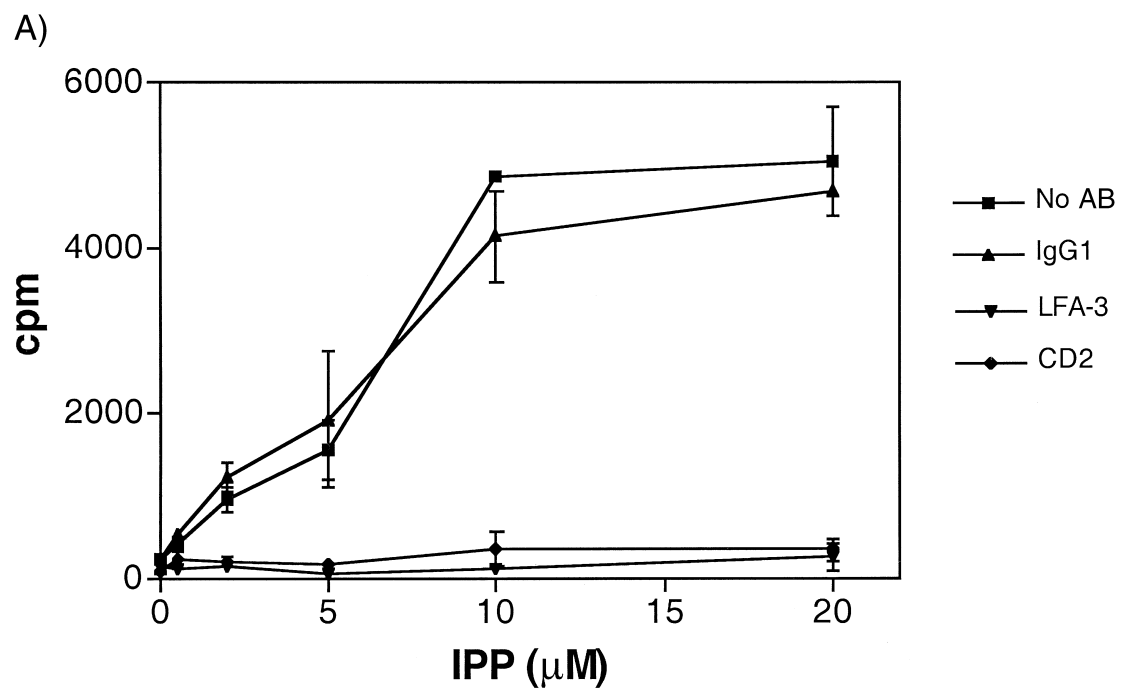

B)

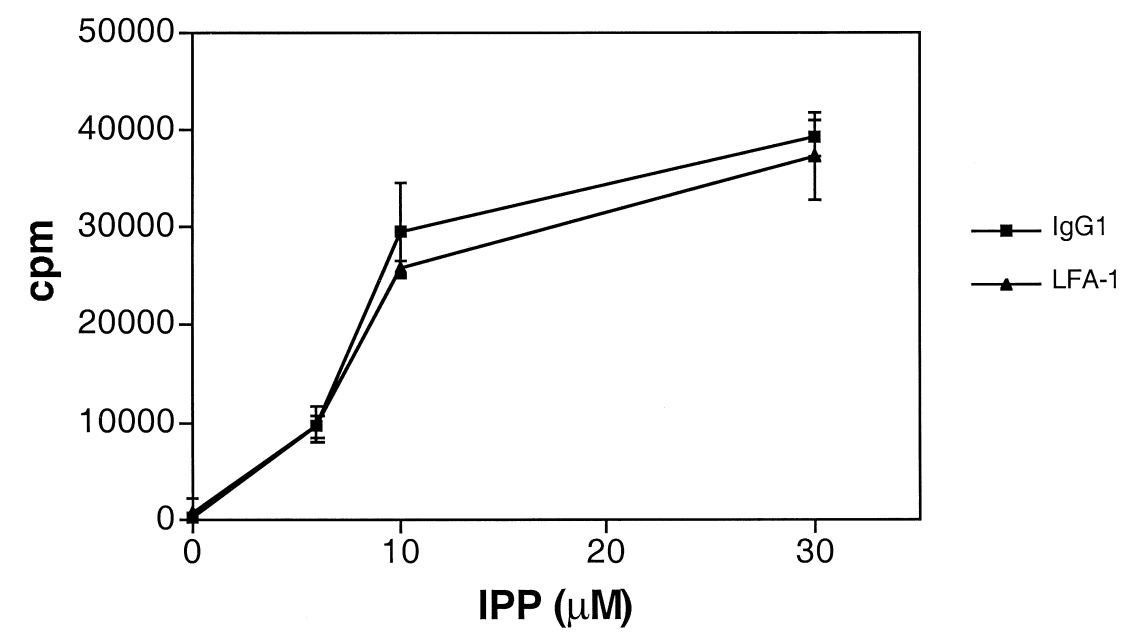

Fig. 5. Anti-CD2 and anti-LFA-3 inhibit the $\mathrm{V} \gamma \mathbf{9} / \mathrm{V} \delta 2 \mathrm{~T}$-cell response to a range of IPP concentrations. $\mathrm{V} \gamma 9 / \mathrm{V} \delta 2 \mathrm{~T}$ cells (clone RO 18) were stimulated with the indicated concentration of IPP using irradiated LCL72 1 cells as antigen-presenting cells. Anti-CD2 or anti-LFA-3 (A, C) strongly in- hibited proliferation $(p<0.02)$ and TNF- $\alpha$ release $(p<0.02)$; whereas, anti-LFA-1 (B, D) had no significant effect $(p>0.05)$. The experiments were repeated with 4 different clones $(12.3 .15,12.3 .12$, RO5, RO18).

Continued on next page. 
C)
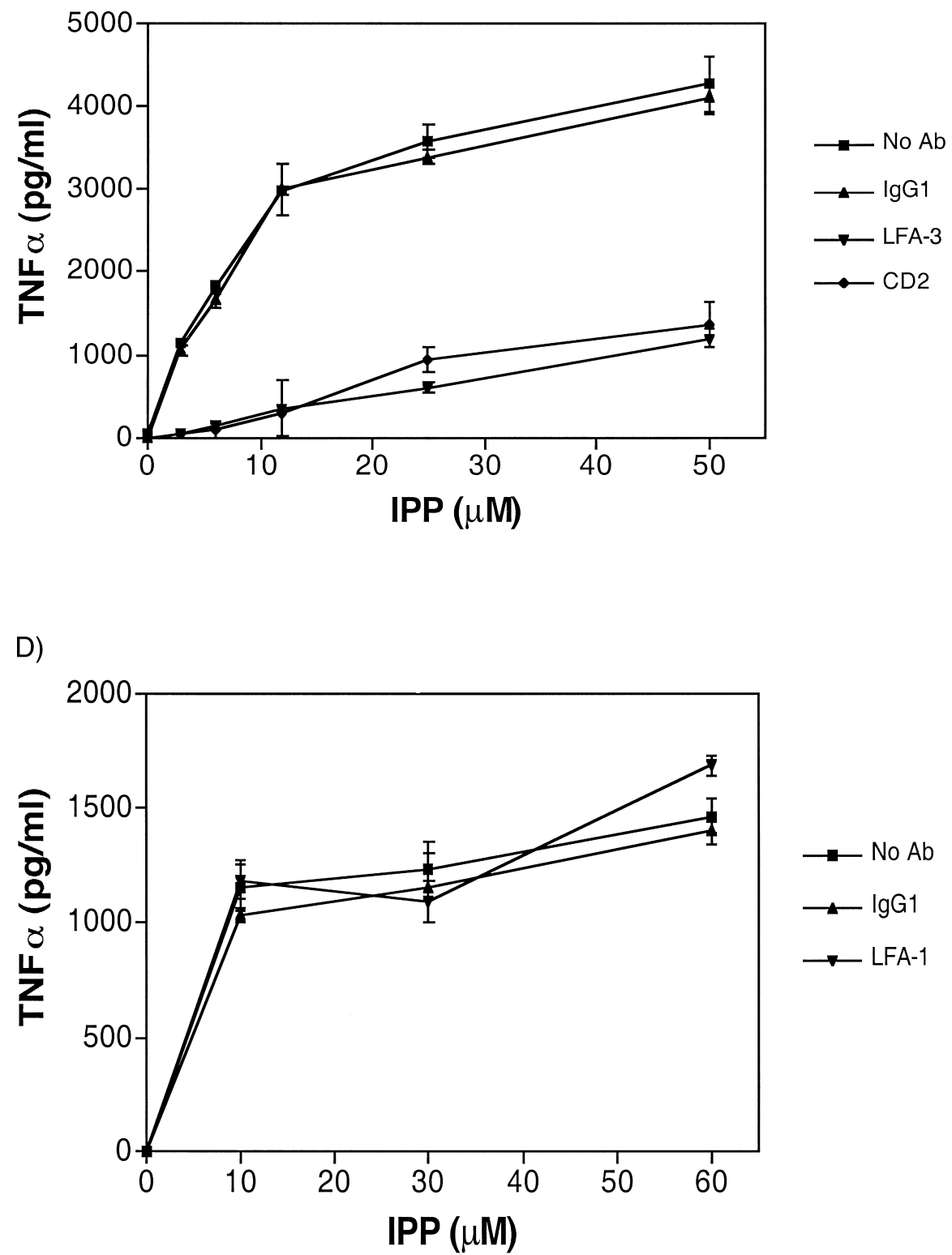

Fig. 5. Continued.

presence of anti-CD2 or anti-LFA-3 was comparable to the control (Fig. 8). This indicates that the blocking of CD2-LFA-3 interactions, followed by the functional inhibition of $\mathrm{V} \gamma 9 / \mathrm{V} \delta 2 \mathrm{~T}$ cells had no substantial influence on the antigen induced TCR downregulation.

\section{Discussion}

Human $\gamma \delta \mathrm{T}$ lymphocytes display potent responses to many antigenic entities of bacterial, protozoal, viral and tumor origin $(19,29-31)$, but the specifics of their protective function and the mechanisms of their regulation remain unknown. The positive effect of APCs on the $\gamma \delta$ T-cell response to IPP suggests that accessory molecules may influence the response. The present experiments provide insights into the regulation of $\mathrm{V} \gamma 9 / \mathrm{V} \delta 2 \mathrm{~T}$-cell activities and address the role of specific accessory molecules.

It has been shown that both LFA-1 and $\mathrm{CD} 2$ are required for $\mathrm{CD}^{+} \alpha \beta$ T cells to kill target cells $(11,15)$. LFA- 1 appears to be the primary molecule that mediates the effectortarget cell contact and CD2 additionally mediates the adhesion among effector and target cells (32). The data in this study strongly sug- 


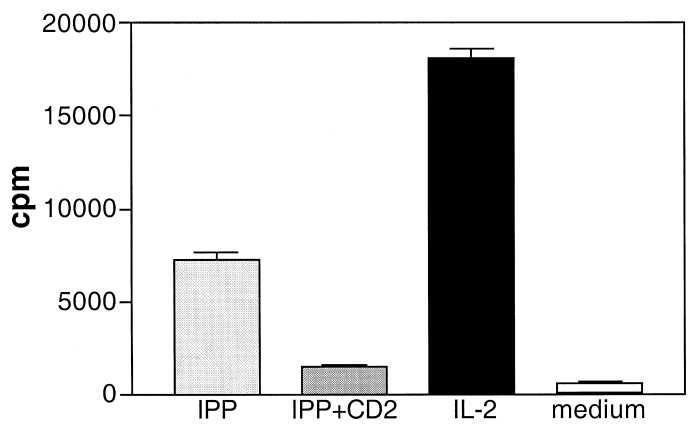

Fig. 6. Anti-CD2 treated $V \gamma 9 / V \delta 2 ~ T$ cells show decreased secretion of IL-2. V $\gamma 9 / \mathrm{V} \delta 2$ T cells (Clone RO5) were stimulated with $20 \mu \mathrm{M}$ of isopentenyl pyrophosphate (IPP) in the presence of anti-CD2 or the isotype control antibody. Twenty-four hours later, the supernatants were used to stimulate CTLL-2 cells. Anti-CD2 blocked the interleukin-2 (IL-2) secretion $(p<0.0002)$. CTLL-2 cells cultured with $100 \mathrm{U} / \mathrm{ml} \mathrm{IL-2}$ served as a positive control. Two other tested clones (12.3.15, RO18) provided similar results (not shown). gest that, similar to $\alpha \beta$ T cells, the LFA-1 molecule is important in the contact between the target cell and the cytotoxic $\mathrm{V} \gamma 9 / \mathrm{V} \delta 2 \mathrm{~T}$ cells. In contrast to $\alpha \beta \mathrm{T}$ cells, the potential accessory role of CD2 in $\mathrm{V} \gamma 9 / \mathrm{V} \delta 2$ effector-target interactions is dispensable, since anti-CD2 or antiLFA-3 have practically no detectable effect on V $\gamma$ 9/V $\delta 2$ T-cell cytotoxicity against Daudi cells.

Although LFA-1 seems to play an important role in the mechanism of $\mathrm{V} \gamma 9 / \mathrm{V} \delta 2 \mathrm{~T}$-cell cytotoxicity, it is not required for $\mathrm{V} \gamma 9 / \mathrm{V} \delta 2 \mathrm{~T}$ cells to respond to IPP. In contrast, in $\alpha \beta \mathrm{T}$ cells, LFA-1 can effectively enhance the antigenic response (28). The cell-mediated cytotoxicity is usually dependent on stable effectortarget conjugates that require the LFA-1 function (11). Our results imply that stable cell-cell conjugates may not be required for the IPP response of $\mathrm{V} \gamma 9 / \mathrm{V} \delta 2 \mathrm{~T}$ cells.

A)

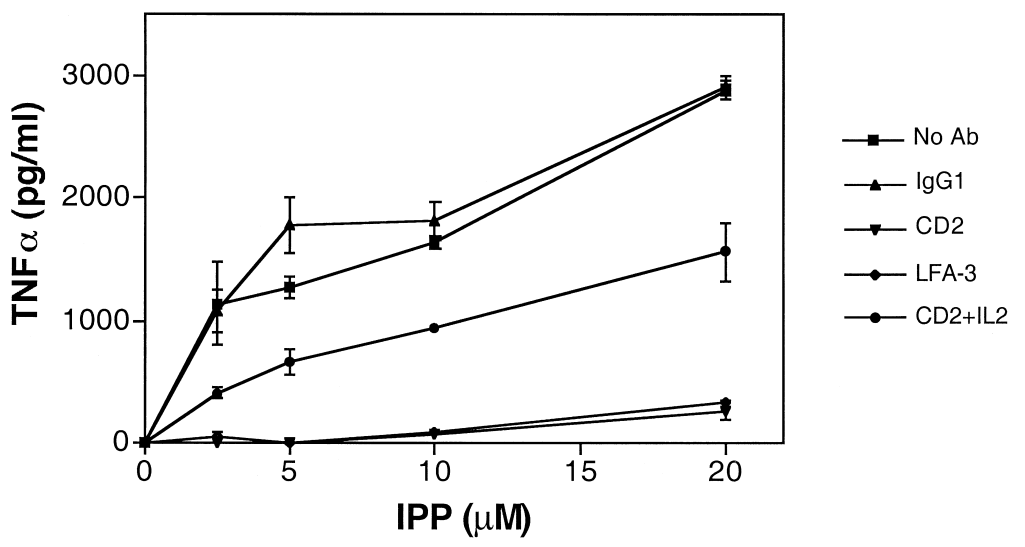

B)

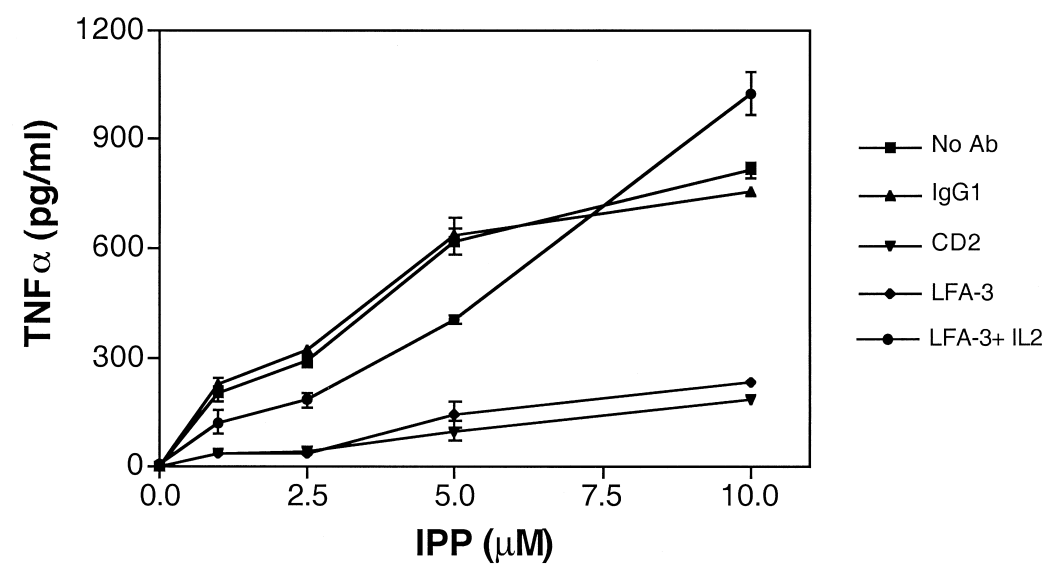

Fig. 7. IL-2 can counteract the CD2/LFA-3 inhibition of the $\mathrm{V} \gamma \mathbf{\gamma} / \mathrm{V} \delta 2 \mathrm{~T}$-cell response to IPP. $\mathrm{V} \gamma 9 / \mathrm{V} \delta 2 \mathrm{~T}$ cells were stimulated with $20 \mu \mathrm{M}$ isopentenyl pyrophosphate (IPP) in the presence of indicated antibody. The addition of $100 \mathrm{U} / \mathrm{ml} \mathrm{IL-2}$ could restore the secretion of tumor necrosis factor-alpha (TNF- $\alpha$ ) in the presence of inhibitory anti-CD2 $(\mathrm{A} ; p<0.04)$ or anti-LFA-3 (B; $p<0.006)$. No detectable levels of TNF- $\alpha$ were induced by the addition of IL-2 alone in the absence of antigenic stimulation. 


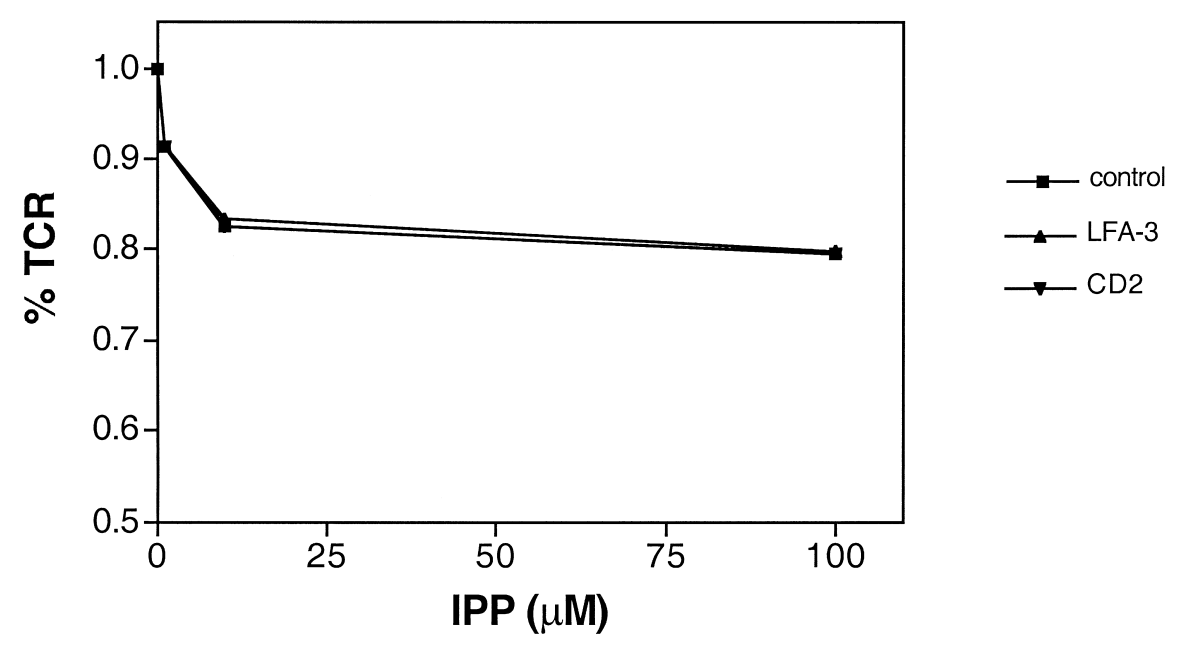

Fig. 8. Anti-CD2 or anti-LFA-3 does not influence the antigen-induced $T$-cell receptor (TCR) downregulation. $\mathrm{V} \gamma 9 / \mathrm{V} \delta 2 \mathrm{~T}$ cells were stimulated with the given concentration of isopentenyl pyrophosphate (IPP) using LCL72 1 cells as antigen-presenting cells. The number of TCRs remaining on the cell surface after stimulation with IPP was quantified with Quantum Sim-

The mechanism of the inhibition by antiCD2 antibodies has been studied in $\alpha \beta$ T cells, resulting in a suggestion that anti-CD2 inhibits the expression of the functional IL-2 receptor (33). This is clearly not the case in our experiments with $\mathrm{V} \gamma 9 / \mathrm{V} \delta 2 \mathrm{~T}$-cell clones. Our results indicate that functional IL-2 receptors are expressed on $\mathrm{V} \gamma 9 / \mathrm{V} \delta 2 \mathrm{~T}$ cells after stimulation in the presence of anti-CD2. The possible explanation that the expression of IL-2 receptors was caused by in vitro culture of $\mathrm{V} \gamma 9 / \mathrm{V} \delta 2 \mathrm{~T}$ cells is unlikely, because the $\mathrm{V} \gamma 9 / \mathrm{V} \delta 2 \mathrm{~T}$ cells could only respond to IL-2 after the IPP stimulation. Thus the anti-CD2 inhibitory effect on the proliferation of IPP-stimulated $\mathrm{V} \gamma 9 / \mathrm{V} \delta 2 \mathrm{~T}$ cells was more likely to be due to an inadequate secretion of proliferative cytokines. This was further supported by the finding that exogenous IL-2 could reverse the anti-CD2 inhibitory effect on $\mathrm{V} \gamma 9 / \mathrm{V} \delta 2 \mathrm{~T}$-cell proliferation (data not shown).

The anti-CD2 antibody used in this study does not induce any intracellular phosphorylation when binding to the CD2 molecule and its effects are attributable solely to the deficit of CD2 signaling caused by the disrupted interactions between CD2 and LFA-3 (34). The ability of IL-2 to restore the TNF- $\alpha$ response of $\mathrm{V} \gamma 9 / \mathrm{V} \delta 2 \mathrm{~T}$ cells in the presence of anti-CD2 suggests that the CD2 signals induced by the inter- ple Cellular beads kit (Flow Cytometry Standards, Research Triangle Park, NC). The results are expressed by plotting the concentration of IPP (on the abscissa) against the percentage of TCRs remaining on cell surface (on the ordinate). No statistically significant differences $(p>0.05)$ were observed.

action with LFA-3 can be successfully substituted by signaling through the IL-2 receptor to proceed with the antigen-induced cytokine production. Neither the signaling through CD2 nor the signals through the IL-2 receptor are fully understood. Interestingly, both of them can activate PI3 kinase $(35,36)$, which in turn, activates transcription factors important for entering cell cycle (36). Some accessory molecules mediate costimulatory signals that can modulate the $\alpha \beta$ TCR downregulation induced by antigenic exposure (28). However, our experiments with $\mathrm{V} \gamma 9 / \mathrm{V} \delta 2 \mathrm{~T}$-cell clones indicate that the blocking of the CD2 signal important for the DNA synthetic and cytokine responses does not influence to the process of antigen-induced TCR downregulation in these cells.

The interactions of accessory molecules (such as LFA-3 or ICAMs) with their T-cell co-receptors, such as CD2 or LFA-1, appear to check the plasticity of $\mathrm{V} \gamma 9 / \mathrm{V} \delta 2$ T-cell activation, allowing exquisite control of effector functions. Our study shows that the accessory costimulation of $\mathrm{T}$ cells stimulated through the TCR is regulated in a somewhat different fashion in $\gamma \delta$ T cells, compared with $\alpha \beta$ T cells. Addressing these differences in detail in future experiments may bring a better understanding of the mechanisms by which a successful co- 
ordinated immune response is induced. The costimulatory signals are most likely to be involved in the expansion phase of the immune response when proliferative cytokines such as IL-2 are the main limiting factors for generating high numbers of antigen-specific T cells. In addition, similar (but negative) signals may be important for the termination phase of the immune response, when the downmodulation of T-cell immunity is necessary to prevent immunopathology or the development of autoimmunity. Thus, the exact knowledge of unique pathways activated by individual classes of accessory molecules and T-cell co-receptors, their cross talk and the regulation of their expression may be crucial when designing novel strategies for vaccination, immunotherapies and the treatment of autoimmune diseases.

\section{Acknowledgments}

This work was supported by grants from the NIH (AI42712 and RR00167) and is publication no. 40-019 of the Wisconsin Regional Primate Research Center.

\section{References}

1. Malkovsky M. (1992) The function and specificity of $\gamma \delta$ T cells. Vaccine Res. 1: 183-191.

2. De Libero G. (1997) Sentinel function of broadly reactive human $\gamma \delta \mathrm{T}$ cells. Immunol. Today 18: 22-26.

3. Bukowski JF, Morita CT, Brenner MB. (1999) Human $\gamma \delta \mathrm{T}$ cells recognize alkylamines derived from microbes, edible plants, and tea: implications for innate immunity. Immunity 11: 57-65.

4. Bukowski JF, Morita CT, Tanaka Y, Bloom BR, Brenner MB, Band H. (1995) V $\gamma 2$ V $\delta 2$ TCRdependent recognition of non-peptide antigens and Daudi cells analyzed by TCR gene transfer. J. Immunol. 154: 998-1006.

5. Tanaka Y, Morita CT, Tanaka Y, Nieves E, Brenner MB, Bloom BR. (1995) Natural and synthetic non-peptide antigens recognized by human $\gamma \delta$ T cells. Nature 375: 155-158.

6. Valitutti S, Lanzavecchia A. (1997) Serial triggering of TCRs: a basis for the sensitivity and specificity of antigen recognition. Immunol. Today 18: 299-304.

7. Mazza G, Housset D, Piras C, Gregoire C, Lin SY, Fontecilla-Camps JC, Malissen B. (1998) Glimpses at the recognition of peptide/MHC complexes by $\mathrm{T}$ cell antigen receptors. Immunol. Rev. 163: 187-196.
8. Bretscher P. (1992) The two-signal model of lymphocyte activation twenty-one years later. Immunol. Today 13: 74-76.

9. Springer TA. (1990) Adhesion receptors of the immune system. Nature 346: 425-433.

10. Springer TA, Dustin ML, Kishimoto TK, Marlin SD. (1987) The lymphocyte function-associated LFA-1, CD2 and LFA-3 molecules: cell adhesion receptors for the immune systems. Annu. Rev. Immunol. 5: 223-252.

11. Davignon D, Martz E, Reynolds T, Kurzinger K, Springer TA. (1981) Monoclonal antibody to a novel lymphocyte function associated antigen (LFA-1): mechanisms blockade of T lymphocyte mediated killing and effects on other $\mathrm{T}$ and $\mathrm{B}$ lymphocyte function. J. Immunol. 127: 590-595.

12. Moingeon $\mathrm{P}$, Chang HC, Sayer PH, et al. (1989) The structural biology of CD2. Immunol. Rev. 111: 111-114.

13. Dustin ML, Selvaraj $P$, Mattaliano RJ, Springer TA. (1987) Anchoring mechanisms for LFA-3 cell adhesion glycoprotein at membrane surface. Nature 329: 846-848.

14. Seed B. (1987) An LFA-3 cDNA encodes a phospholipid-linked membrane protein homologous to its receptor CD2. Nature 329: 840-842.

15. Van De Wiel-van Kemenade E,Te Velde AA, De Bore AJ, et al. (1992) Both LFA-1 positive and deficient $\mathrm{T}$ cell clones require the CD2/LFA-3 interaction for specific cytolytic activation. Eur. $J$. Immunol. 22: 1467-1475.

16. Howard FD, Moingeon $\mathrm{P}$, Moebius U, et al. (1992) The CD3 zeta cytoplasmic domain mediates CD2-induced T cell activation. J. Exp. Med. 176: 139-145.

17. Wesselborg S, Janssen O, Pechhold K, Kabelitz D. (1991) Selective activation of gamma/delta + $\mathrm{T}$ cell clones by single anti-CD2 antibodies. J. Exp. Med. 173: 297-304.

18. Bluestone JA, Khattri R, Sciammas R, and Sperling AI. (1995) TCR $\gamma \delta$ cells: a specialized T cell subset in the immune system. Annu. Rev. Immunol. 11: 307-353.

19. Poccia F, Gougeon M-L, Bonneville M, LopezBotet M, Morette A, Battistini L, Wallace M, Colizzi V, Malkovsky M. (1998) Innate T cell immunity to nonpeptidic antigens. Immunol. Today 19: 253-256

20. Morita CT, Beckman EM, Bukowski JF, Tanaka Y, Band H, Bloom BR, Golan DE, Brenner MB. (1995) Direct presentation of nonpeptide prenyl pyrophosphate antigens to human gamma delta T cells. Immunity 3: 495-507.

21. Fisch P, Malkovsky M, Braakman E, et al. (1990) Gamma/delta $T$ cell clones and natural killer cell clones mediate distinct patterns of non-major histocompatibility complexrestricted cytolysis. J. Exp. Med. 171: 1567-1579.

22. Malkovsky M, Medawar PB, Thatcher et al. (1985) Acquired immunological tolerance of 
foreign cells is impaired by recombinant interleukin 2 or vitamin A acetate. Proc. Natl. Acad. Sci. U.S.A. 82: 536-538.

23. Malkovsky M, Asherson GL, Stockinger B, Watkins MC. (1982) Nonspecific inhibitor released by $\mathrm{T}$ acceptor cells reduses the production of interleukin-2. Nature 300: 652-655.

24. Malkovsky M, Loveland B, North $M$, et al. (1987) Recombinant interleukin-2 directly augments the cytotoxicity of human monocytes. $\mathrm{Na}$ ture 325: 262-265.

25. Gramzinski RA, Adams E, Gross JA, Goodman TG, Allison JP, Lefrancois L. (1993) T cell receptor-triggered activation of intraepithelial lymphocytes in vitro. Int. Immunol. 5: 145-153.

26. Wen L, Barber DF, Pao W, Wong FS, Owen MJ, Hayday A. (1998) Primary gamma delta cell clones can be defined phenotypically and functionally as Th1/Th2 cells and illustrate the association of CD4 with Th2 differentiation. J. Immunol. 160: 1965-1974.

27. Valitutti S, Muller S, Cella M, Padovan E, Lanzavecchia A. (1995) Serial triggering of many $T$ cell receptors by a few peptide-MHC complexes. Nature 375: 148-151.

28. Bachmann MF, McKall-Faienza K, Schmits R, Bouchard D, Beach J, Speiser DE, Mak TW, Ohashi PS. (1997) Distinct roles for LFA-1 and CD28 during activation of naive T cells: adhesion versus costimulation. Immunity 7: 549-557.

29. Fisch P, Malkovsky M, Kovats et al. (1990) Recognition by human $\mathrm{V} \gamma 9 / \mathrm{V} \delta 2 \mathrm{~T}$ cells of a
groEL homolog on Daudi Burkitt's lymphoma cells. Science 250: 1269-1273.

30. Hass, W, Pereira, P, Tonegawa, S. (1993) Gamma/delta T cells. Annu. Rev. Immunol. 11: 637-685.

31. Wallace, M, Malkovsky, M. Carding, SR. (1995) Gamma/delta T lymphocytes in viral infections. J. Leukoc. Biol. 58: 277-283.

32. Moingeon $\mathrm{P}$, Chang HC, Wallner BP, Stebbins C, Frey AZ, Reinherz EL. (1989) CD2-mediated adhesion facilitates $\mathrm{T}$ lymphocyte antigen recognization function. Nature 339: 312-314.

33. Stohl W, Linker-Israeli M. (1989) Inhibitory effects of anti-CD2 monoclonal antibodies on interleukin 2 production and interleukin 2 receptor expression in anti-CD3-induced $\mathrm{T}$ cell activation. Cell Immunol. 120: 351-365.

34. Schwarz M, Bohuslav J, Majdic O, Stockinger H, Knapp W, Holter W. (1995) Identification of the TS2/18-recognized epitope on the CD2 molecule as a target for suppression of $\mathrm{T}$ cell cytokine synthesis. J. Immunol. 154: 5813-5820.

35. Shimizu Y, Mobley JL, Finkelstein LD, Chan AS. (1995) A role for phosphatidylinositol 3kinase in the regulation of beta 1 integrin activity by the CD2 antigen. J. Cell Biol. 131: 1867-1880.

36. Brennan $P$, Babbage JW, Burgering BM, Groner B, Reif K, Cantrell DA. (1997) Phosphatidylinositol 3-kinase couples the interleukin-2 receptor to the cell cycle regulator E2F. Immunity 7: 679-689. 